Vol. 6, Num. 2, 2021

\title{
FEATURES OF THE IMPLEMENTATION OF SMART TECHNOLOGIES IN THE MINE
}

\author{
${ }^{1}$ Maksym Butov, ${ }^{2}$ Tetyana Pavych, ${ }^{1}$ Yaroslav Paramud \\ ${ }^{1}$ Lviv Polytechnic National University, 12, Bandera Str, Lviv, 79013, Ukraine. \\ ${ }^{2}$ MedBridge Inc, 1633 Westlake Ave, Seattle, WA, 98109, USA \\ Authors'e-mail: maksym.butov.mki.2020@lpnu.ua; tpavych98@gmail.com; yaroslav.s.paramud@lpnu.ua
}

https://doi.org/10.23939/acps2021.

Submitted on 11.10.2021

(C) Butov M., Pavych T., Paramud Y., 2021

\begin{abstract}
The basic methods and principles of mine safety systems have been considered in the paper. The algorithm of one possible smart device (smart helmet) is depicted. This algorithm describes the basic principles of this device. The device allows to find danger in the environment where the miner works, as well as monitors the condition of the miner. It can also quickly analyze this information and report the danger when it is detected. The system has been developed and programmed including basic modules for implementing this algorithm. The results of the comparative analysis of the new system showed an increase in the level of safety by $45 \%$ compared to other systems.
\end{abstract}

Index Terms: Computer system, Warning systems, sensors, smart technology.

\section{INTRODUCTION}

Much attention has been paid to portable (electric) devices since Google Inc. released its Google Glass. Handheld devices have been able to gain a significant place in the consumer electronics market in a short period of time and they are considered a new tool to meet the needs of many industries. For example, the construction industry has introduced the use of portable devices in the workplace to monitor health and safety by detecting approaching hazards and physiological monitoring of construction workers. The logistics industry has begun using glove scanners to scan barcodes to simplify non-hands-on work, and some insurance companies have already promoted the use of portable devices to encourage healthier eating. In addition, devices such as fitness trackers are being used by medical professionals to obtain physiological, behavioral and contextual data for diagnosis and treatment. While much research is still ongoing to determine how these devices can be better adapted to different industries, the use of portable device technology is expected to expand significantly in the near future.

In mines, unfortunately, most of the time old stationary sensors and warning systems are still used, which does not provide a guarantee that a gas leak will not occur outside the sensor range and the miner will be informed about it [1]. Also, none of the existing systems process the information immediately, but pass it outside to the control room, thus precious time is wasted [2]. Therefore, a new system is needed, which should include not only a ground monitoring system, but also an autonomous handheld module that will process the data and inform the miner of the danger both inside the mine and about the health of the miner [3].

The introduction of new smart technologies should be based on modern microcontrollers [4], a gas sensor [5], temperature sensor [6], heart rate sensor [7], light sensor [8], distance sensor, sound alert device, light warning devices, vibrating alert device, LCD display, flashlight, data transmission device, overhead monitoring complex.

The systems that now provide occupational safety monitoring in the mine are divided into two types. The first most common ones do not meet modern safety standards and have a number of drawbacks. An example of such systems is "Radius-2" [9]. The others are too large-scale and expensive. An example of such systems - "SBGPS" [10].

A review of literary sources indicates the relevance and feasibility of conducting research on the implementation of modern smart technologies in the mine.

\section{COMPARATIVE ANALYSIS OF EXISTING SYSTEMS FOR MONITORING LABOR SAFETY IN THE MINES}

The main disadvantages of a considerable part of the existing systems, ensuring work safety in a mine, are stationary location of sensors and lack of monitoring of miners' condition from outside. Examples of such systems are Radius -2, SUBR-1P, SBGPS. The first two systems are the most widespread and used, the last one requires sufficient investment and time for its implementation.

$$
\text { A. RADIUS-2 AND SUBR-1P }
$$

Radius-2 and SUBR-1P are the most common systems that ensure work safety in the mine. They are based on the technology of signal transmission through the rock strata. These systems are the most reliable, because they are not 
afraid of cable breaks, as the transmission is carried out by low-frequency electromagnetic waves using a frequency grid from the lower range of $25 \mathrm{~Hz}$ to $2500 \mathrm{~Hz}$ in increments of $50 \mathrm{~Hz}$. The coverage area of the "Radius-2" complex is up to $2000 \mathrm{~m}$ deep through the mountain massif and up to $15 \mathrm{~km}$ along the mine field. The transmitting antenna of the complex, which is a grounded dipole or frame covering the mine field, can be suspended on the poles of power lines, laid on the ground surface in the ground or underground mine workings, safe with respect to gas and dust. The antenna is connected to the power amplifier PDD, which, depending on the geometric dimensions of the mine field, the geoelectric properties of rocks selected from a range of $1.25,2.5,5.0,10,15 \mathrm{~kW}$ [9].

\section{B. $S B G P S$}

The SBGPS system is one of the most modern and technologically advanced on the market. The underground part is a network of base stations (BS) and individual notification devices. The distance between each base station is $200-500 \mathrm{~m}$, for full radio coverage of the entire area of the excavation.

The system uses a hybrid connection method because it uses Mesh-Net technology.

The individual notification device is an ordinary miner's flashlight, attached to the helmet. In addition, it also consists of a WiFi module, through which communication with the infrastructure is continuously ensured, a voice processor, as well as a methane sensor, which allows for a more complete aero gas control in workings, supplementing the stationary sensors. The operating time of this light is 44 hours [10].

The above-ground part consists of a control panel, located at the dispatcher, and a server that continuously receives and processes data from the sensors.

This system continuously receives and processes signals from both stationary sensors and from sensors on the miner's head. If it is detected that the concentration of methane exceeds the permissible norm, this information about the danger is immediately transmitted to the dispatcher. And he transmits a safety signal to the BS, which in turn transmits it to the miner.

In fact, such types of radio communication can effectively cope with the task of emergency notification of underground personnel only in small mines. If you try to implement it in a mine with a very long excavation, the number of BS will be extremely large and this implementation will turn out to be too expensive. Another disadvantage is that the information is processed outside, not inside, and there is no monitoring of the state of the miner himself.

\section{FORMULATION OF THE PROBLEMS}

Today, the mining industry is one of the most dangerous and underdeveloped in the use of portable smart devices. Although miner safety is one of the most important issues in this field, the systems that provide it are in one case too outdated, or not up to code, and in another case, they are so expensive and extensive that the benefit from their use is minimal. At present in the countries with developed mining industry, such as Japan, Poland, Australia, USA, Great Britain, etc., they use different types of systems ensuring safety of miners in a mine on the basis of modern information technologies.

The general structure of such systems consists of two main parts:

1) Ground complex of devices:

- Central monitoring department (production and dispatching department). The monitoring system operates from a continuous power supply, in case of failure of voltage supply, the system begins to be powered from the standby power grid or generator. All characteristics of the system are in the central monitoring department.

- The production department can use the information, but cannot interfere with the system; the maintenance personnel can understand the condition of the environment in the mine via the local network.

2) Underground complex of devices:

- Devices in the mine - gas sensors installed to monitor the condition of the air in the workings.

- Signal conversion and transmission devices.

- Air velocity sensors, which are usually installed in the same workings, as well as in the ventilation shafts of the head ventilation fan.

- Automatic switches that ensure the power is turned off when the concentration of hazardous gas exceeds a predetermined threshold.

All of these sensors are stationary, although in mine development these sensors are placed in places where there is an increased risk of gas that will threaten the lives of miners, this does not guarantee that the dangerous gas will appear in this particular place and not elsewhere. And since the warning systems are located in specific places, if the miner is far enough away from that location, or is working near a loud device, he simply won't hear it [1].

Another big disadvantage of such systems is that almost all have information transmitted to the outside, then processed, and only then, in case of danger, is it transmitted back to the mine and only then the warning systems are activated. As a consequence, in the case of a breakdown, the signal may simply not reach the miner at the right moment. Also, none of these systems tell the miner exactly what happened [2].

The general structure of the labor safety monitoring system in the mine is shown in Fig. 1.

From this, we can conclude that the problem of ensuring the safety of the miner in the mine is quite relevant and important to create a new system, using smart technology. This system will include an above-ground monitoring system for the condition of the mine, as well as the health of the miners themselves, and an autonomous portable module that will independently notify the miners of the danger and send the information about the condition of the miner and the mine workings, to the outside [3]. 


\section{THE AIM OF THE WORK}

The aim of the work is to increase the level of safety in one of the least developed industries - the mining industry by introducing modern intelligent technologies, as well as to reduce the number of incidents related to material and human losses. Among others: to improve one of the most problematic characteristics of older systems, namely the coverage of the mine, and to provide autonomy of parts of system.

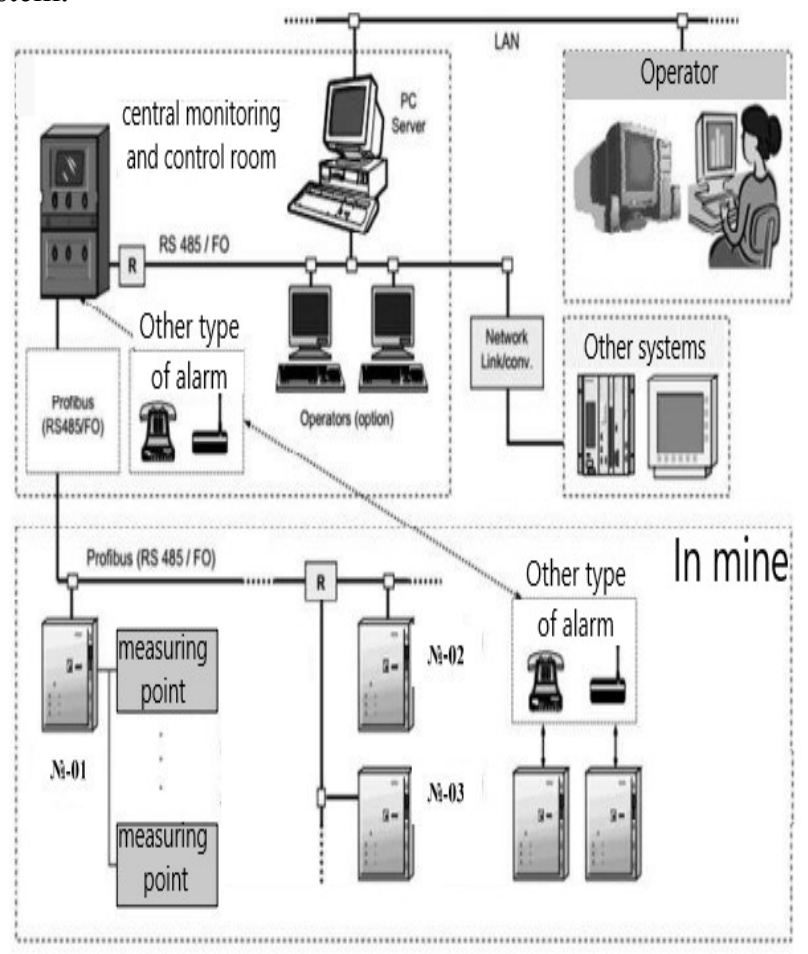

Fig. 1. The general structure of the labor safety monitoring system in the mine.

\section{THEORETICAL FOUNDATIONS OF SMART MINE}

A smart mine must consist of an above-ground and underground set of devices that can interact with each other or work autonomously of each other. Structural diagram of a smart mine is shown in Fig. 2. Therefore, the smart mine system must include an autonomous portable module, the first part of which will be attached to the miner's helmet, and the second part - to his arm. The helmet will contain sensors, a microcontroller, warning and data transmission devices.

Owing to this module, a number of problems will be solved, namely:

- Since the sensors are now portable, the entire working area of the mine will be covered, not just where the sensors are installed.

- Owing to the microcontroller, the system will be able to process the information immediately and report the danger, instead of waiting for a response from the above-ground part.
- The warning devices will always be close to the miner, so he will always be notified of the danger.

- Owing to the transmission devices the aboveground monitoring complex will always have information not only about the mine workings but it will also be able to see information about the state of health of each worker, namely his condition and where he is. Also, in the event of an accident, the dispatcher at the top will be able to inform the closest miners, who can quickly rectify the situation.

- Since this module is self-contained, it can continue to work and ensure the safety of the miner even in the event of a break in communication or if it is used without an above-ground part.

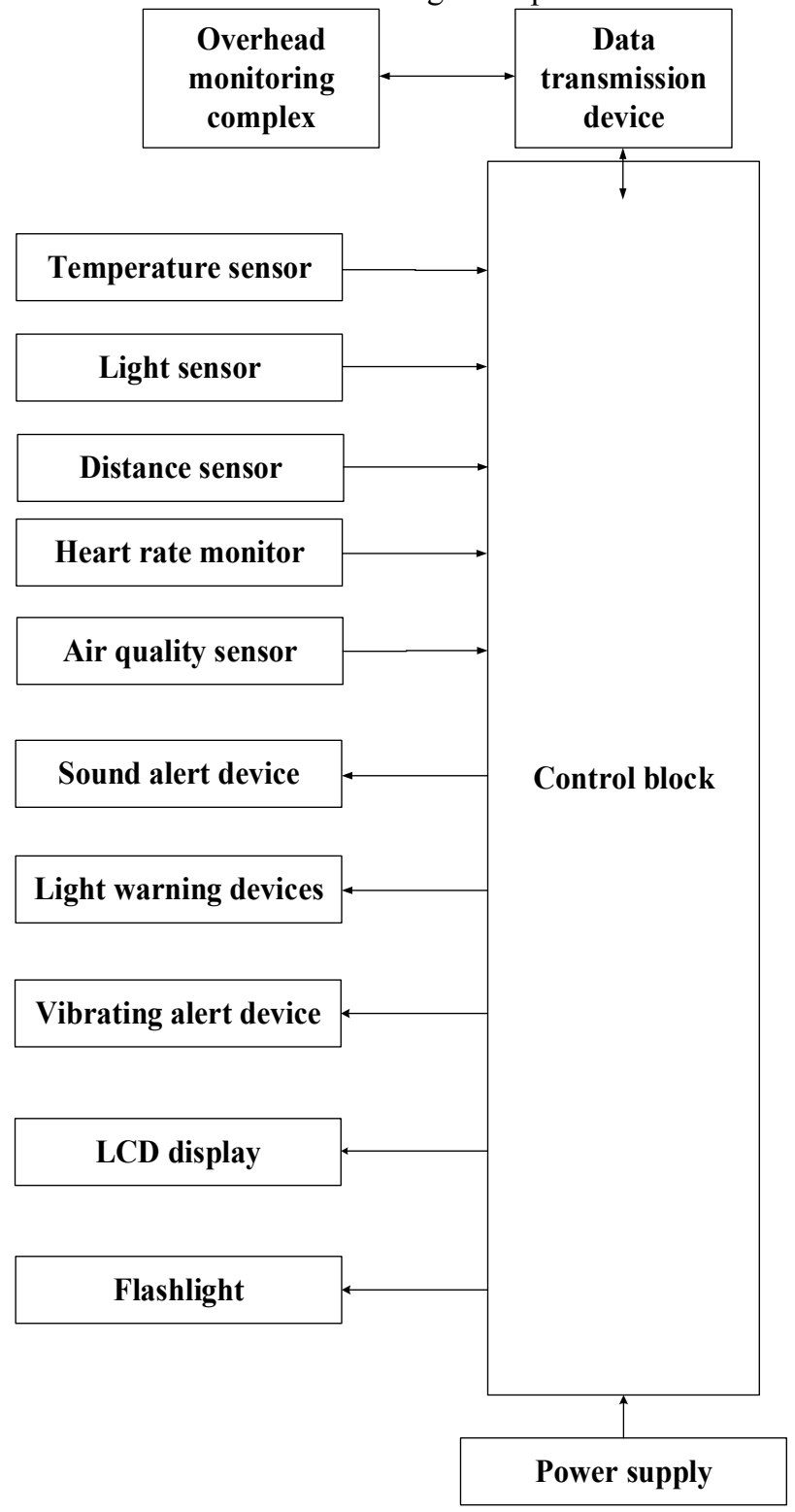

Fig. 2. Structural scheme of a computer system for monitoring labor safety in a mine. 
A screen (like a watch) will be placed on the miner's arm, which will help the miner understand what kind of accident has occurred, as well as monitor the battery charge, because if the battery charge is low, the sensitivity of the sensors may be reduced or their operation will be suspended altogether.

To ensure reliability in the system, each base station will be additionally connected to several other system components. As a consequence, as a result of a break in the main line, the signal will communicate wirelessly with the nearest base station

This connection technology is called Mesh-Net, which ensures that if there are problems along the way, the signal will move from one node to another, looking for a path to the destination.

The system will also be open to new functionality that will further improve mine safety monitoring.

\section{BASIC PRINCIPLES OF OPERATION OF THE NEW SYSTEM}

Generalized algorithm of the autonomous system device is shown in Fig. 3.

The first step initializes all necessary foams of the system and switches on all subsystems: gas sensor, temperature sensor, light and pulsometer as well as light, vibration and sound alarms. The required default data for the sensors is also set.

The next step is the process of obtaining the data required for analysis from the gas sensor.

After that, the received value is analyzed for exceeding the permissible gas concentration, and if it is exceeded, a signal is sent to the alarm device. In turn, the frequency of operation of these devices depends on how much the concentration limit is exceeded.

The next step is to obtain the temperature sensor data required for analysis.

After that, the received value is analyzed for exceeding the allowable temperature, and if it is exceeded, a signal is sent to the alarm device. In turn, as in the case of the gas sensor, the frequency of operation of these devices depends on the allowable temperature is exceeded.

The next step involves obtaining the necessary data from the light sensor.

After that, it is checked whether the received value of the illuminance value is lower than the nominal value. If this is the case, a signal is sent to the lantern and it is switched on. Also, if the lantern has already been on and the value of the illuminance value is above or equal to the rated value, a signal is given to turn it off and the lantern is turned off to save power.

Then, the next step, the data from the heart rate monitor is received.

The value received is then analyzed. If it is lower or higher than the norm, a signal is sent to one of the warning lights, and the frequency of its operation will depend on whether the norm has been lowered or exceeded.

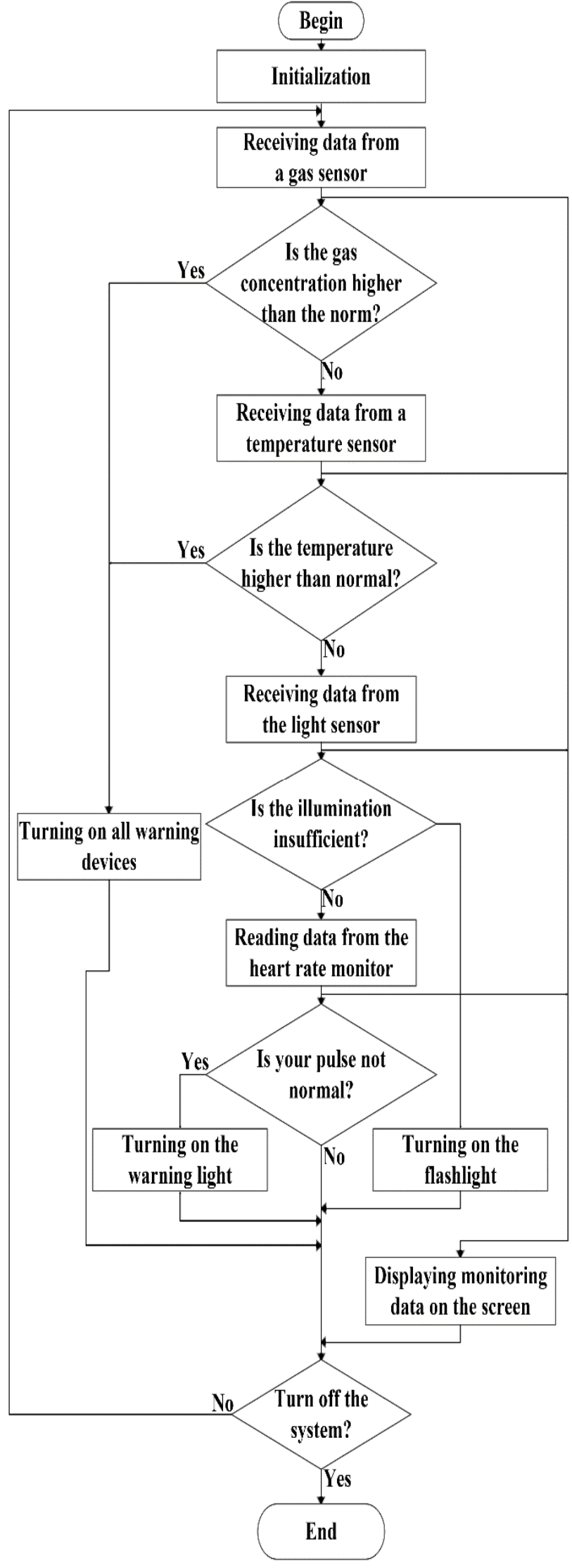

Fig. 3. Generalized algorithm of the autonomous system device. 
Also, all data of the miner's condition monitoring is always displayed on the screen as well as data of his working environment.

This algorithm is in fact an endless cycle, as all measurements are cyclic. The exit from this cycle is to turn off the device.

\section{FUNCTIONAL PRINCIPLES OF SOFTWARE AND HARDWARE IMPLEMENTATION OF THE MAIN COMPONENTS OF THE AUTONOMOUS PART OF THE SYSTEM AND TESTING OF THE OPERATION ALGORITHM}

The functioning of all nodes of the microcontroller is provided by the clock pulses generated by the clock generator. The microcontroller ATmega328 includes a built-in oscillator for these clock pulses. But in Arduino UNO the clock of this microcontroller is controlled by an external clock with a $12 \mathrm{Mhz}$ crystal oscillator. It is connected to the microcontroller through the outputs XTAL1 and XTAL2 [4]. The wiring diagram is shown in Fig. 4. The gas sensor MQ-2, which measures the concentration of gases harmful to the miner, is connected via output $\mathrm{A} 0$ on the module to the analog output $\mathrm{A} 5$ on the Arduino. The VCC and GND outputs on the module are connected directly to the $5 \mathrm{~V}$ and GND outputs respectively. No additional elements need to be connected [5].

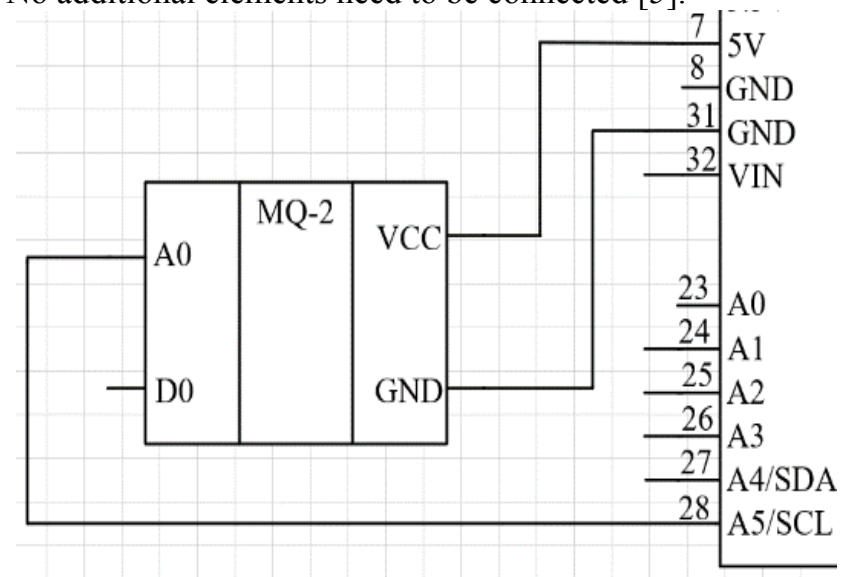

Fig. 4. Wiring diagram of the MQ-2 gas sensor.

The DS18B20 temperature sensor, which measures high and low temperatures for miner operation, is connected via the DQ output on the module to the digital input D11 on the Arduino. The VDD and GND outputs on the module are connected directly to the $5 \mathrm{~V}$ and GND outputs respectively. It is also mandatory to connect an additional $4.7 \mathrm{kOhm}$ resistor from the signal wire to the power wire. This is done due to the fact that the signal transmitted through the signal wire is quite small, so it is pulled up by the additional power from the 5V [6]. The wiring diagram is shown in Fig. 5.

The pulsometer XD-58C, measuring the miner's heart rate too high or too low, is connected via output S0 on the module to the analog input A4 on the Arduino. The VCC and GND outputs on the module are connected directly to the $5 \mathrm{~V}$ and GND outputs respectively. No additional elements need to be connected [7]. The wiring diagram is shown in Fig. 6.

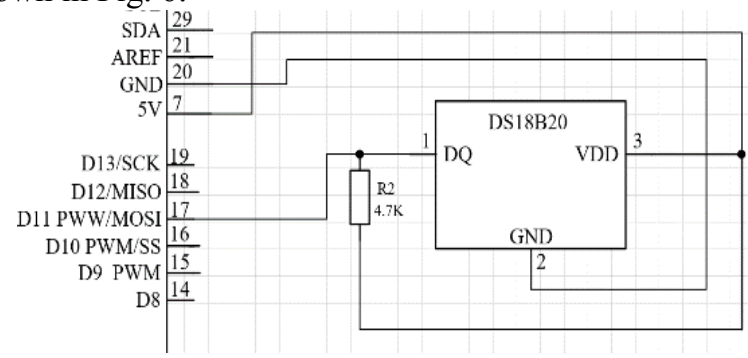

Fig. 5. Wiring diagram of the DS18B20 temperature sensor.

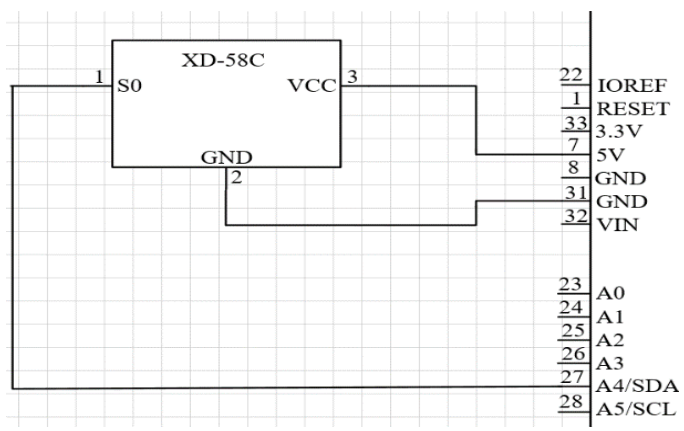

Fig. 6. Wiring diagram of the XD-58C heart rate sensor.

The light sensor (photoresistor), which checks enough light in the mine working for comfortable work of the miner, is realized as a voltage divider. The connection diagram is shown in Fig. 7. One output it is connected to GND and the other to the analog output A0 and the voltage source. To the voltage source it is connected through a 10 $\mathrm{kOhm}$ resistor. As a result, in this connection scheme the maximum voltage value will correspond to absolute darkness and the minimum value to good light. Also, the connected resistor performs an additional function, namely to limit the amount of current in the branch, so that when the resistance of the fully illuminated resistor disappears the connection foams do not burn out [8].

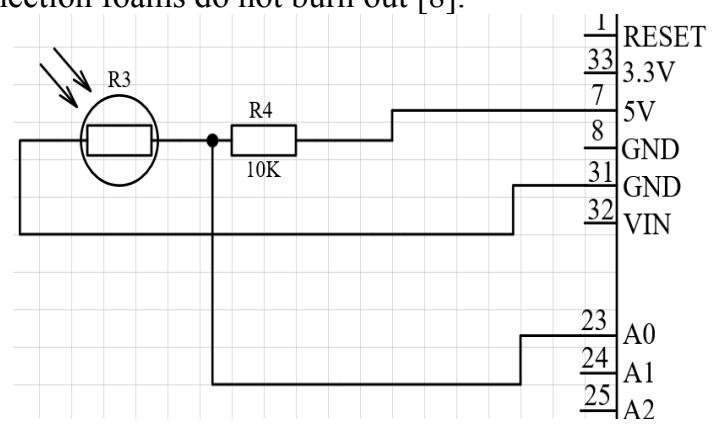

Fig. 7. Wiring diagram of the GL5516 light sensor.

The software implementation of this algorithm assumes the presence of such architectural modules of the program:

- Module for receiving input data - designed to receive input data from sensors and write them into variables for subsequent analysis.

- Module for data processing - analyzes data from the gas sensor, temperature sensor, pulsometer, and 
light sensor. Each gas concentration, temperature or pulse value has its own code block with its own parameters for alarm systems. In the case of the light sensor, it analyzes whether the light level is less than normal.

- Module of notification system launch - includes light, sound and vibration notification systems in case of receiving disappointing data from the data processing module.

- Module of information output - performs a second output of information about the miner's state and the state of the environment on the screen.

Since this system consists of 4 sensors, let's test the operation of each of them separately. First, let's check if the system outputs correct and expected data from all sensors.

Table 1 shows the data that our system receives under normal conditions. Where the first value is the heart rate value for a person, the second is the gas concentration in the room, the third is the darkness value, and the last is the temperature in the room. When you look at these values, you can immediately see that they are all normal.

Table 1

Data obtained from sensors

\begin{tabular}{llll}
\hline \hline Pulse value & $\begin{array}{l}\text { Gas } \\
\text { value }\end{array}$ & $\begin{array}{l}\text { Light } \\
\text { value }\end{array}$ & $\begin{array}{l}\text { Temperature } \\
\text { value }\end{array}$ \\
\hline 75 & 37 & 156 & 22 \\
75 & 36 & 157 & 22 \\
75 & 36 & 157 & 22 \\
75 & 36 & 157 & 22 \\
75 & 37 & 156 & 22 \\
\hline \hline
\end{tabular}

In order to test the gas sensor, a jet of methane gas was sprayed on it. This was done with an ordinary lighter. As it can be seen in Table 2, the gas concentration increased, as a result of which the red LED on the circuit began to blink, the vibration motor started to work and a sound was heard from the loudspeaker, reporting the danger.

\begin{tabular}{llll}
\multicolumn{5}{c}{ Gas sensor operation testing } \\
\hline \hline Pulse value & Gas & Light & Temperature \\
& value & value & value \\
\hline 75 & 40 & 156 & 22 \\
75 & 142 & 157 & 22 \\
75 & 218 & 156 & 22 \\
75 & 341 & 157 & 22 \\
75 & 457 & 156 & 22 \\
\hline \hline
\end{tabular}

In order to test the temperature sensor, the air around it was heated with the same lighter. As it can be seen in Table 3 , the temperature value increased to 34 degrees Celsius. As a consequence of this, just as in the case of the gas sensor, the red LED started blinking, the vibration motor started working and a sound was heard from the loudspeaker, reporting the danger. Testing temperatures below normal was not carried out because it was not necessary. After all, if the sensor perfectly detects the temperature above the norm, it will also detect lower temperatures.
Table 3

Testing the operation of the temperature sensor

\begin{tabular}{llll}
\hline \hline Pulse value & $\begin{array}{l}\text { Gas } \\
\text { value }\end{array}$ & $\begin{array}{l}\text { Light } \\
\text { value }\end{array}$ & $\begin{array}{l}\text { Temperature } \\
\text { value }\end{array}$ \\
\hline 75 & 34 & 156 & 22 \\
75 & 33 & 156 & 27 \\
75 & 33 & 157 & 27 \\
75 & 34 & 156 & 33 \\
75 & 34 & 156 & 34 \\
75 & 33 & 156 & 36 \\
\hline \hline
\end{tabular}

To test the light sensor, it was covered with an opaque object. As a result, the darkness index increased, and thus the illuminance decreased. This process can be seen in Table 4. As a result, the white LED on the breadboard lit up, which in this case represents a miner's lantern.

Table 4

Testing the operation of the light sensor

\begin{tabular}{llll}
\hline \hline Pulse value & $\begin{array}{l}\text { Gas } \\
\text { value }\end{array}$ & $\begin{array}{l}\text { Light } \\
\text { value }\end{array}$ & $\begin{array}{l}\text { Temperature } \\
\text { value }\end{array}$ \\
\hline 75 & 34 & 156 & 22 \\
75 & 33 & 537 & 22 \\
75 & 33 & 533 & 22 \\
75 & 34 & 527 & 22 \\
75 & 34 & 525 & 22 \\
75 & 35 & 524 & 22 \\
\hline \hline
\end{tabular}

To test the heart rate monitor, several physical exercises were performed. As it can be seen in Table 5, the heart rate value increased after completing these exercises. This caused the green LED to start blinking, thus communicating the danger. Testing for a lower heart rate was not done, as it is not possible to do so under normal conditions.

Table 5

Testing the heart rate monitor

\begin{tabular}{llll}
\hline \hline Pulse value & $\begin{array}{l}\text { Gas } \\
\text { value }\end{array}$ & $\begin{array}{l}\text { Light } \\
\text { value }\end{array}$ & $\begin{array}{l}\text { Temperature } \\
\text { value }\end{array}$ \\
\hline 125 & 34 & 156 & 22 \\
125 & 33 & 156 & 22 \\
125 & 33 & 157 & 22 \\
125 & 33 & 157 & 22 \\
125 & 35 & 157 & 22 \\
\hline \hline
\end{tabular}

Consequently, we can conclude that this warning system for hazardous working conditions in the mine works properly, there are no problems in its operation, it correctly processes the data and turns on the necessary warning devices at the right time.

\section{DISCUSSIONS}

The results of monitoring workplace safety in the mine with the new system, which meets modern standards, proved the effectiveness of its use. The new system provided autonomy of the system components, which the old systems did not have at all. Coverage of the mine was increased to $100 \%$ compared with systems such as Radius2. In addition, the new system is expected to reduce the 
number of human losses by about $60 \%$ by monitoring the health of the miner.

In conclusion, it was found by expert evaluation that the overall safety level in the mine increased by $45 \%$ compared to other systems.

\section{CONCLUSIONS}

Structural solutions, hardware and algorithmic means of a system for maintaining safe working conditions at a mine based on modern computer technologies were proposed.

Hardware and software implementation of the algorithm of the autonomous part, which is part of the computer system of safety monitoring in the mine, is very important. This will help improve safety in one of the most underdeveloped industries, the mining industry, by about $45 \%$. Underdeveloped countries that will implement this system will finally be able to ensure the safety of their miners.

By using autonomous modules in the system, the system will be able to continue to function if the modules lose communication between each other. Also, owing to the use of an autonomous module, coverage of the mine is $100 \%$. Since the system is open, in the future some new modules can be added to it, which will further increase the level of safety of the miner. Also, since the system monitors not only the state of the environment in which the miner works, but also the state of the miner, which none of the systems given in the article does, it will reduce the number of human losses by about $60 \%$.

Therefore, we can say that the introduction of such a system will make the miners' work safer.

\section{References}

[1] Golin'kof V. I., Lebedev Y. Y., Mukha O. O. (2012). Ventilyatsiya shakht $i$ rudnikov [Ventilation of mines and mines], 272 p. Available at: https://www.geokniga.org/bookfiles/geokniga-ventilyaciyashaht-i-rudnikov.pdf (Accessed: 18 November 2021).

[2] Papushyn Y, L. (2007). Osnovy avtomatyzatsiyi hirnychoho vyrobnytstva [Fundamentals of mining automation], $170 \mathrm{p}$. Available http://repository.kpi.kharkov.ua/bitstream/KhPI-

Press/36392/1/Book_2007_Papushyn_Osnovy_avtomatyzats ii.pdf (Accessed: 18 November 2021).

[3] Denysenko V. P., Verba R. V., Abakumova E. M. (2011). Problemy potochnoho prohnozuvannya metanovydilennya $u$ hirnychykh vyrobkakh vuhil $\square$ nykh shakht [Problems of current forecasting of methane release in mine workings of coal mines], pp. 138 - 148. Available at: http://dspace.nbuv.gov.ua/bitstream/handle/123456789/9966 4/17-Denisenko.pdf?sequence=1 (Accessed: 18 November 2021).

[4] Novatskyi A. O. (2012). Proektuvannya mikroprotsesornykh system na bazi AVR-mikrokontroleriv [Design of microprocessor systems based on AVR-microcontrollers], 470 p. Available at: https:/ela.kpi.ua/bitstream/123456789/1889/1/11-12-197.pdf (Accessed: 25 may 2020).

[5] Yogesh M. (2021). Prohramuvannya ta vzayemodiya $z$ Arduino [Programming and Interfacing with Arduino], $278 \mathrm{p}$. https://www.twirpx.com/file/3516754/

November 2021).

[6] Petyn V. A. (2015). Proekty $z$ vykorystannyam kontrolera Arduino [Projects using an Arduino controller], 464 p. Available at: https://ru.pdfdrive.com/e152129937.html (Accessed: 18 November 2021).

[7] Mohammed S., Carla S., Sultan A., (2019). Innovatsiyi v informatsiynykh systemakh i tekhnolohiyakh dlya pidtrymky doslidzhen $\square u$ navchanni [Innovation in Information Systems and Technologies to Support Learning Research], 640 p. Available at: https://link.springer.com/book/10.1007/978-3-030-36778-7 (Accessed: 18 November 2021).

[8] James F. K., Harold T. (2013). Pryhody Arduyino: Vtecha zi stantsiyi Blyznyukiv [Arduino Adventures: Escape from Gemini Station], 232 p. Available at: http://volthauslab.com/ebooks/Arduino/arduino_adventures. pdf (Accessed: 29 October 2021).

[9] Radius-nvic.ru (2020). "Radius-2” system. [online] Available at: http://radius-nvic.ru/page7059197.html (Accessed: 18 November 2021).

[10] Granch.ru (2020). "SBGPS" system. [online] Available at: http://www.granch.ru/ru/sistemybezopasnosti/mnogofunktsionalnaya-sistema-bezopasnostisbgps-gornass (Accessed: 18 November 2021).

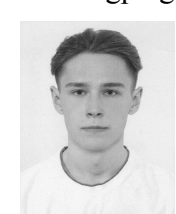

smart mine.

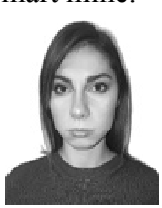

Maksym Butov in 2020 received a Bachelor's degree in computer engineering at Lviv Polytechnic National University. From 2020 to 2022 he is getting Master's degree in the field of Computer System and Networks.

His research interests include subsystems for

Tetyana Pavych. Senior Business Analyst at MedBridge Inc. Bachelor's degree of Management Information System in 2019 at Northwood University, Midland, MI, USA. Business Career Program graduated in 2021 from Computer Systems Institute, Chicago, IL, USA. Her research is in the CRM management, business intelligence, data analysis area.

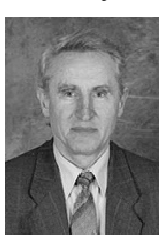

Yaroslav Paramud. Ph.D., Assoc. Prof at Computer Engineering Department of Lviv Polytechnic National University. Scientific interests include processing radar information, research algorithms, and structures of specialized computing devices and systems.

The number of scientific publications - more than 30, has 13 Inventor's Certificates. 